\title{
Rastreabilidade da farinha de carne e ossos bovinos em ovos de poedeiras comerciais pela técnica dos isótopos estáveis do carbono e nitrogênio ${ }^{1}$
}

\author{
Juliana Célia Denadai², Carlos Ducatti ${ }^{3}$, José Roberto Sartori², Antonio Celso Pezzato², \\ Rosana Gottmann ${ }^{4}$
}

\author{
1 Parte do projeto financiado pela FAPESP No 2006/55306-3. \\ 2 Departamento de Melhoramento e Nutrição Animal, FMVZ, Universidade Estadual Paulista, Campus de Botucatu, SP. \\ ${ }^{3}$ Centro de Isótopos Estáveis, Departamento de Física e Biofísica, IBB, Universidade Estadual Paulista, Campus de Botucatu, SP. \\ 4 Programa de Pós-Graduação em Zootecnia, Faculdade de Medicina Veterinária e Zootecnia - Universidade Estadual Paulista - \\ Botucatu, SP, Brasil.
}

RESUMO - Objetivou-se com este estudo rastrear a inclusão de farinha de carne e ossos bovinos em dietas para poedeiras comerciais, por meio da análise dos ovos e de suas frações (gema e albúmen), pela técnica dos isótopos estáveis do carbono e nitrogênio e avaliar o índice analítico mínimo detectável. Foram utilizadas 240 galinhas poedeiras da linhagem Shaver White de 73 semanas de idade, distribuídas em delineamento inteiramente casualizado, com cinco tratamentos e seis repetições. Foram avaliados cinco níveis de inclusão $(0 ; 1,5 ; 3,0 ; 4,5$ e 6,0\%) de farinha de carne e ossos bovinos em uma dieta à base de milho e farelo de soja. No 35o dia, foram tomados aleatoriamente 24 ovos por tratamento: 12 serviram para amostragem de gema e albúmen e os outros 12 para amostragem do ovo (gema + albúmen). Os resultados isotópicos foram submetidos à análise multivariada de variância e, a partir das matrizes de erro, com 95\% de confiança, foram determinadas elipses para identificar as diferenças entre os resultados obtidos com o fornecimento das dietas experimentais e a dieta controle, sem farinha de carne e ossos bovinos. No ovo e na gema, a partir do par isotópico da dieta com 3,0\% de farinha de carne e ossos, houve diferenciação do par do tratamento controle, enquanto, no albúmen, a diferenciação ocorreu a partir do nível de 1,5\% de farinha de carne e ossos bovinos na dieta. Pela técnica dos isótopos estáveis, é possível rastrear o uso de farinha de carne e ossos bovinos na alimentação de poedeiras; no albúmen, o nível mínimo de inclusão detectável é de 1,5\% e, no ovo e na gema, 3,0\%.

Palavras-chave: aves, carbono-13, certificação, ingrediente de origem animal, nitrogênio-15

\section{Traceability of bovine meat and bones meal in eggs of commercial laying hens through carbon and nitrogen stable isotopes technique}

\begin{abstract}
The objective of this study was to trace the inclusion of bovine meat and bones meal in diets of laying hens analyzing eggs and theirs fractions (yolk and albumen), by carbon and nitrogen stable isotopes, as well as to evaluate the detectable analytical minimal index. Two hundred and forty (240) Shaver White laying hens aging 73 weeks were distributed in a completely randomized design, with five treatments and six replicates. Five increasing levels $(0 ; 1.5 ; 3.0 ; 4.5$ and $6.0 \%)$ of bovine meat and bones meal in a diet based on corn and soybean meal were evaluated. On the $35^{\text {th }}$ day, 24 eggs per treatment were randomly collected, twelve for yolk and albumen sampling and another twelve for egg (yolk + albumen) sampling. The isotopic results were analyzed in a multivariate analysis of variance. Through an error matrix (95\% confidence) the ellipses were determined to identify the differences between results obtained with supply of experimental diets and control diet, without $3 \%$ bovine meat and bones meal. In egg and yolk, from the isotopes pair of the diet with $3 \%$ bovine meat and bones meal, there was differentiation in the pair of the control treatment, whereas in the albumen it was possible to detect the 1.5 bovine meat and bones meal. The stable isotopes technique is able to trace the use of bovine meat and bones meal in laying hens feed; the minimal traceable level of inclusion is $1.5 \%$ in the albumen and $3.0 \%$ in the egg and yolk.
\end{abstract}

Key Words: animal origin ingredients, birds, carbon-13, certification, nitrogen-15

\section{Introdução}

A avicultura brasileira, para fornecer aos consumidores produtos de qualidade, utiliza diversas ferramentas de gestão e controle de qualidade, como o APPCC (análise de perigos e pontos críticos de controle) ou o BPF (boas práticas de fabricação), porém não dispõe de sistema de identificação oficial como o SISBOV (Sistema Brasileiro de Identificação e Certificação de Origem Bovina e Bubalina), específico para a cadeia de bovinos e bubalinos (Cerutti, 2002). 
Além dessas ferramentas de gestão e controle de qualidade, seria desejável que houvesse análise de contraprova para atestar a veracidade das informações constantes no histórico alimentar de lotes de produtos diferenciados e monitorar o processo de rastreabilidade, fornecendo laudos técnicos para as auditorias, como instrumento de confiabilidade (Oliveira et al., 2010). Muitos métodos têm sido propostos para identificar a presença de subprodutos de origem animal em rações para animais, entre eles, hibridização de DNA, ELISA e PCR (Bloch Junior, 2002), contudo, esses métodos não identificam o subproduto de origem animal no produto final, ou seja, carne e ovos.

A espectrometria de massas, por meio da análise da razão isotópica carbono-13 $\left({ }^{13} \mathrm{C}\right)$, tem sido usada com sucesso para testar a autenticidade e a qualidade de vários produtos, como sucos de frutas (Bricout \& Koziet, 1987; Koziet et al., 1993), vinhos (Martin et al., 1988), méis (Brookes et al., 1991; White et al., 1998) e produtos lácteos (Rossmann et al., 2000; Manca et al., 2001). No entanto, a linha de pesquisa desenvolvida no Centro de Isótopos Estáveis Ambientais da UNESP, campus de Botucatu, visa rastrear subprodutos de origem animal na dieta de aves no produto final (Oliveira et al., 2010; Carrijo et al., 2006; Móri et al., 2007, Gottmann et al., 2008; Móri et al., 2008), e foi fundamentada no estudo de Piasentier et al. (2003), que certificaram a origem geográfica e os tipos de alimentação de ovinos por meio da razão isotópica do carbono em associação à do nitrogênio.

Denadai et al. (2005), em estudo de ovos de dois produtores da região de Bastos, São Paulo, pelo sistema de duplo eixo isotópico $\left(\delta^{13} \mathrm{C}\right.$ e $\left.\delta^{15} \mathrm{~N}\right)$, analisaram ovos cujas informações do produtor descreviam uso apenas de produtos de origem vegetal na alimentação das poedeiras e os demais, uso de produtos de origem animal. Os ovos possuíam, segundo os autores, padrões isotópicos distintos, sugerindo a possibilidade de rastrear a inclusão de farinha de origem animal na alimentação das poedeiras e sua detecção no produto final (ovo).

Neste estudo, objetivou-se rastrear a inclusão de farinha de carne e ossos bovinos em dietas para poedeiras comerciais, por meio da análise dos ovos e de suas frações (gema e albúmen), pela técnica dos isótopos estáveis do carbono e do nitrogênio, e avaliar o índice analítico mínimo detectável.

\section{Material e Métodos}

O experimento foi conduzido na UNESP, campus de Botucatu, Faculdade de Medicina Veterinária e
Zootecnia, nas instalações do setor de Avicultura da Fazenda Experimental Edgárdia, no período de 14 de setembro a 19 de outubro de 2006. Foram utilizadas 240 galinhas poedeiras da linhagem Shaver White com 73 semanas de idade, alojadas em gaiolas metálicas de dimensões: $1,00 \mathrm{~m}$ de comprimento $\times 0,45 \mathrm{~m}$ de profundidade e $0,40 \mathrm{~m}$ de altura, com comedouros do tipo calha, independentes, e bebedouros do tipo linear, com água corrente, ambos localizados frontalmente. A densidade utilizada foi de oito aves por gaiola e, tanto a água como a ração, foram fornecidas à vontade. O programa de iluminação artificial adotado foi de 16 horas de luz/dia.

As aves que nunca haviam recebido anteriormente dietas contendo farinhas de origem animal passaram a receber as dietas experimentais durante 35 dias, a fim de substituir o carbono e o nitrogênio dos tecidos envolvidos na produção dos ovos pelos da nova dieta. O período experimental foi determinado considerando os dados de Denadai et al. (2005), de 24,5 a 33,6 dias para substituição total do carbono nos ovos, quando avaliaram metabolicamente quatro dietas $\mathrm{C}_{3}$ e/ou $\mathrm{C}_{4}$ em poedeiras pela técnica dos isótopos estáveis do carbono.

O delineamento experimental foi o inteiramente casualizado, com cinco tratamentos, seis repetições, considerando como repetição uma gaiola. Foram avaliados cinco níveis de inclusão $(0 ; 1,5 ; 3,0 ; 4,5$ e 6,0\%) de farinha de carne e ossos bovinos (FCO_B) na dieta à base de milho e farelo de soja.

Para os teores de proteína, cálcio, fósforo, energia metabolizável e aminoácidos dos ingredientes utilizados no preparo das dietas experimentais, foram considerados os valores descritos por Rostagno et al. (2005). Apenas a farinha de carne e ossos bovinos foi analisada bromatologicamente e apresentou 93,75\% de matéria seca (MS), 45,75\% de proteína bruta (PB), 8,43\% de extrato etéreo (EE), 48,17\% de matéria mineral (MM).

As dietas (Tabela 1) foram formuladas de modo a atender às exigências nutricionais das aves, também estabelecidas por Rostagno et al. (2005), e balanceadas para que os teores fossem isoenergéticos, isoproteicos, isocálcicos, isofosfóricos e isoaminoacídicos para metionina + cistina e lisina.

No 35을 dia, foram tomados aleatoriamente 24 ovos por tratamento (quatro por repetição). Desses ovos, 12 (dois por repetição) serviram para amostragem de gema e albúmen e os outros 12 (dois por repetição) para amostragem do ovo (gema + albúmen). Os ovos para amostragem de gema e albúmen foram separados e armazenados em sacos plásticos devidamente identificados. 
Tabela 1 - Composição percentual e níveis nutricionais calculados das dietas experimentais

\begin{tabular}{|c|c|c|c|c|c|}
\hline \multirow[t]{2}{*}{ Ingrediente (\%) } & \multirow[t]{2}{*}{ Controle } & \multicolumn{4}{|c|}{ Nível de farinha de carne e ossos bovinos } \\
\hline & & $1,5 \%$ & $3,0 \%$ & $4,5 \%$ & $6,0 \%$ \\
\hline Milho moído & 64,91 & 66,12 & 66,33 & 66,39 & 66,42 \\
\hline Farinha de carne e ossos & 0,00 & 1,50 & 3,00 & 4,50 & 6,00 \\
\hline Óleo de soja & 0,45 & 0,06 & 0,00 & 0,00 & 0,00 \\
\hline Calcário calcítico & 9,71 & 9,46 & 9,22 & 9,00 & 8,70 \\
\hline L-lisina & 0,00 & 0,01 & 0,03 & 0,04 & 0,05 \\
\hline Sal comum & 0,35 & 0,35 & 0,35 & 0,35 & 0,35 \\
\hline Suplemento vitamínico ${ }^{1}$ & 0,10 & 0,10 & 0,10 & 0,10 & 0,10 \\
\hline Suplemento mineral $^{2}$ & 0,10 & 0,10 & 0,10 & 0,10 & 0,10 \\
\hline Caulim & 0,00 & 0,00 & 0,47 & 1,03 & 1,15 \\
\hline Total & 100,00 & 100,00 & 100,00 & 100,00 & 100,00 \\
\hline \multicolumn{6}{|l|}{ Níveis nutricionais calculados } \\
\hline Fósforo disponível (\%) & 0,37 & 0,37 & 0,37 & 0,37 & 0,37 \\
\hline Fibra bruta $(\%)$ & 2,61 & 2,58 & 2,56 & 2,50 & 2,44 \\
\hline Metionina (\%) & 0,41 & 0,41 & 0,41 & 0,40 & 0,40 \\
\hline Metionina + cistina (\%) & 0,68 & 0,68 & 0,68 & 0,68 & 0,68 \\
\hline Lisina (\%) & 0,79 & 0,79 & 0,79 & 0,79 & 0,79 \\
\hline
\end{tabular}

Os ovos foram homogeneizados em liquidificador e também armazenados em sacos plásticos identificados. As amostras, depois de identificadas, foram congeladas a $-20^{\circ} \mathrm{C}$ até o processamento.

$\mathrm{Na}$ etapa de processamento, as amostras foram descongeladas e secas em estufa de ventilação forçada (Marconi - modelo MA 035) a $56{ }^{\circ} \mathrm{C}$, por 24 horas, para as amostras de albúmen, e por 48 horas, para as de ovo e gema. Depois de secas, amostras de aproximadamente 2,0 $\mathrm{g}$ foram moídas criogenicamente em moinho criogênico Spex-modelo 6750 freezer/mill. Neste moinho, foram individualmente acondicionadas em frascos de policarbonato, juntamente com uma barra magnética, imersos em nitrogênio líquido $\left(-196{ }^{\circ} \mathrm{C}\right)$. Pelo impacto entre a amostra e a barra magnética submetida a um campo magnético oscilante (15 impactos/s), pulverizou-se a amostra.

O programa utilizado na moagem das amostras incluiu duas etapas: pré-congelamento de um minuto; e congelamento e pulverização de três minutos. Este procedimento permitiu obter partículas com granulometria menor que $60 \mu \mathrm{m}$ (Licatti, 1997; Rosa et al., 2002; Ducatti, 2004).

Após a moagem, as amostras de ovos (gema + albúmen) e gemas foram acondicionadas em papel-filtro devidamente identificados para extração da gordura. Tieszen et al. (1983) afirmam que frações com quantidade considerável de lipídeos são relativamente pobres em carbono-13 se comparadas às que possuem pouco lipídeos. Por meio do aparelho de Soxhlet, as amostras foram imersas em éter etílico (PA) e mantidas sob temperatura em torno de 55 e $65{ }^{\circ} \mathrm{C}$ por 4 horas. Após este período, as amostras foram suspensas durante uma hora para que apenas éter recondicionado as lavasse. Posteriormente, foram retiradas do aparelho e secas em estufa de ventilação forçada durante uma hora para evaporação do éter. Essas amostras foram moídas novamente para homogeneização.

As análises foram realizadas no Centro de Isótopos Estáveis do Instituto de Biociências da UNESP, campus de Botucatu. Em cápsulas de estanho, foram pesados 50 a $60 \mu \mathrm{g}$ e 500 a $600 \mu \mathrm{g}$ de amostras de ovos e suas frações para determinação das razões isotópicas do carbono e nitrogênio, respectivamente. Para ração, a massa utilizada foi de 60 a $70 \mu$ g e 1.600 a $1.700 \mu$ g, respectivamente. As cápsulas foram introduzidas por meio de amostrador automático no analisador elementar (EA 1108 - CHN Fisons Instruments, Rodano, Itália), no qual as amostras foram queimadas para a formação de $\mathrm{CO}_{2}$ e $\mathrm{N}_{2}$. Os gases formados foram separados em coluna cromatográfica gasosa e analisados no espectrômetro de massas de razões isotópicas (Delta S - Finnigan MAT, Bremen, Alemanha).

Os valores das razões isotópicas foram expressos na notação delta $(\delta)$ relativos aos padrões internacionais PeeDee Belemnite (PDB) para o carbono-13 e nitrogênio do ar atmosférico para nitrogênio-15, de acordo com a seguinte equação geral (1) (Ducatti, 2004): 
$\delta_{\text {(amostra, padrão) }}=\left[\left(\mathrm{R}_{\text {amostra }}-\mathrm{R}_{\text {padrão }}\right) / \mathrm{R}_{\text {padrão }}\right] \times 1000$ em que: $\mathrm{R}$ = razão entre o isótopo menos abundante e o mais abundante, em particular ${ }^{13} \mathrm{C} /{ }^{12} \mathrm{C} \mathrm{e}{ }^{15} \mathrm{~N} /{ }^{14} \mathrm{~N}$. Adimensional.

Os resultados isotópicos obtidos foram submetidos à análise multivariada de variância (MANOVA) com auxílio do procedimento GLM do programa estatístico SAS (1996). A partir dos dados gerados pelas matrizes de erro, com 95\% de confiança, foram determinadas regiões (elipses) para verificar as diferenças entre as médias dos tratamentos experimentais (dietas com adição de farinha de carne e ossos bovinos) e a média do grupo controle (dieta estritamente vegetal).

\section{Resultados e Discussão}

Em decorrência do aumento percentual da inclusão de farinha de carne e ossos bovinos nas dietas (Tabela 2), houve enriquecimento nos valores isotópicos de carbono13 e nitrogênio-15. Esse fato ocorreu provavelmente devido às variações na composição percentual dos ingredientes nas dietas. Como estas foram formuladas para ser isocalóricas e isoproteicas entre si, na medida em que aumentou o nível de farinha de carne e ossos na dieta $\left(\delta^{13} \mathrm{C}=-12,82 \pm 0,13\right.$ e $\left.\delta^{15} \mathrm{~N}=7,43 \pm 0,22, \mathrm{n}=2\right)$, diminuiu a de farelo de soja e óleo de soja $\left(\delta^{13} \mathrm{C}=-26,57 \pm 0,35\right.$ e $\delta^{15} \mathrm{~N}=0,43 \pm 0,05 ; \delta^{13} \mathrm{C}=-31,54 \pm 0,21$ e $\delta^{15} \mathrm{~N}=$ ausente, respectivamente, $\mathrm{n}=2$ ) e aumentou a inclusão de milho $\left(\delta^{13} \mathrm{C}=-13,19 \pm 0,03\right.$ e $\left.\delta^{15} \mathrm{~N}=3,57 \pm 0,23, \mathrm{n}=2\right)$. Oliveira et al. (2010), Carrijo et al. (2006), Móri et al. (2007), Gottmann et al. (2008) e Móri et al. (2008) utilizaram farinhas de origem animal na dieta de aves (frangos de corte e codornas) e também encontraram enriquecimento isotópico tanto em $\delta^{13} \mathrm{C}$ quanto em $\delta^{15} \mathrm{~N}$.

O enriquecimento das dietas quanto ao carbono-13 poderia ser conseqüência do enriquecimento isotópico das plantas $\mathrm{C}_{4}$ em comparação às $\mathrm{C}_{3}$ (Vogel, 1993), adicionado ao fato do valor isotópico da farinha de origem animal refletir o sinal isotópico da dieta do animal que a deu origem, variando por volta de 2\%o para o $\delta^{13} \mathrm{C}$ (DeNiro \& Esptein, 1978).

Quanto ao nitrogênio-15, a diminuição da inclusão do farelo de soja, leguminosa que realiza simbiose com micorrizas, de valor isotópico próximo ao padrão (Handley \& Raven, 1992; Werner \& Schimidt, 2002), associada ao aumento do milho, rico isotopicamente em nitrogênio-15, que depende do nitrogênio do solo (Choi et al., 2002) e da farinha de carne e ossos bovinos, também rica em nitrogênio15 , causada pelo reflexo da dieta do animal que a deu origem, associada ao enriquecimento a cada elevação no nível trófico do organismo animal (DeNiro \& Epstein, 1981), poderia ser a causa do enriquecimento dessas dietas.

Nos ovos e suas frações (Tabela 2), o enriquecimento de $\delta^{13} \mathrm{C}$ e $\delta^{15} \mathrm{~N}$ teve comportamento crescente e semelhante ao enriquecimento das dietas, devido aos níveis crescentes de inclusão de farinha de carne e ossos bovinos. Embora cada fração possa apresentar assinatura isotópica distinta, os resultados estão de acordo com relatos de DeNiro \& Epstein $(1976 ; 1978 ; 1981)$ de que o animal é aquilo que consome isotopicamente, com variação em torno de $2 \%$ o para carbono-13 e 3\%o para nitrogênio-15.

Antes do início do experimento, foram coletadas e analisadas isotopicamente amostras de ovos $(n=8)$ e da dieta $(\mathrm{n}=2)$ que as aves vinham recebendo, os quais apresentaram valores de $\delta^{13} \mathrm{C}=-17,88 \pm 0,20 \%$ e e $\delta^{15} \mathrm{~N}=$ $4,07 \pm 0,20 \%$ para os ovos e $\delta^{13} \mathrm{C}=-15,88 \pm 0,08 \%$ e $\delta^{15} \mathrm{~N}=2,28 \pm 0,06 \%$ para as dietas. Com a introdução das dietas experimentais (Tabela 2), esses valores se alteraram, e a mudança isotópica dos ovos acompanhou a mudança da respectiva dieta, comprovando que houve substituição total isotópica dos tecidos que formavam esses ovos, como afirmado por Denadai et al. (2006) de que a substituição total dos carbonos nos ovos levou de 24,5 a 33,6 dias, conforme a mudança das dietas.

Os valores médios de $\delta^{13} \mathrm{C}$ e $\delta^{15} \mathrm{~N}$ encontrados para ovo (gema + albúmen), albúmen e gema foram analisados

Tabela 2 - Valores médios de $\delta^{13} \mathrm{C}$ e $\delta^{15} \mathrm{~N}$ com respectivos desvios-padrão das dietas $(\mathrm{n}=2)$, dos ovos e de suas frações $(\mathrm{n}=12)$

\begin{tabular}{llrrrr}
\hline Nível de farinha de carne e ossos bovinos & \multicolumn{1}{c}{ Dieta } & \multicolumn{1}{c}{ Ovo } & \multicolumn{2}{c}{ Albúmen } \\
\hline Controle & $\delta^{13} \mathrm{C}(\%)$ & $-15,79 \pm 0,08$ & $-18,31 \pm 0,16$ & $-18,28 \pm 0,18$ & $-18,38 \pm 0,10$ \\
& $\delta^{15} \mathrm{~N}(\%)$ & $1,53 \pm 0,03$ & $4,43 \pm 0,22$ & $3,47 \pm 0,18$ & $4,46 \pm 0,19$ \\
$1,5 \%$ & $-15,67 \pm 0,09$ & $-17,77 \pm 0,14$ & $-17,73 \pm 0,19$ & $-17,72 \pm 0,19$ \\
& $\delta^{13} \mathrm{C}(\%)$ & $1,75 \pm 0,06$ & $4,58 \pm 0,14$ & $3,68 \pm 0,15$ & $4,58 \pm 0,17$ \\
$3,0 \%$ & $\delta^{15} \mathrm{~N}(\%)$ & $-15,35 \pm 0,22$ & $-17,43 \pm 0,11$ & $-17,54 \pm 0,18$ & $-17,60 \pm 0,08$ \\
& $\delta^{13} \mathrm{C}(\%)$ & $2,10 \pm 0,06$ & $4,81 \pm 0,23$ & $3,91 \pm 0,15$ & $4,88 \pm 0,28$ \\
$4,5 \%$ & $\delta^{15} \mathrm{~N}(\%)$ & $-14,89 \pm 0,21$ & $-17,32 \pm 0,10$ & $-17,40 \pm 0,13$ & $-17,24 \pm 0,20$ \\
& $\delta^{13} \mathrm{C}(\%)$ & $2,36 \pm 0,11$ & $5,02 \pm 0,11$ & $4,09 \pm 0,07$ & $5,08 \pm 0,13$ \\
$6,0 \%$ & $\delta^{15} \mathrm{~N}(\%)$ & $-14,84 \pm 0,32$ & $-16,88 \pm 0,13$ & $-16,66 \pm 0,18$ & $-16,96 \pm 0,13$ \\
& $\delta^{13} \mathrm{C}(\%)$ & $2,68 \pm 0,06$ & $5,17 \pm 0,23$ & $4,83 \pm 0,13$ & $5,40 \pm 0,12$ \\
\hline
\end{tabular}


estatisticamente e geraram regiões com 95\% de confiança (Figuras 1, 2 e 3). Para que determinado tratamento seja considerado diferente do grupo controle, é necessário que sua região de confiança não sobreponha nenhum eixo do gráfico. $\mathrm{O}$ fato de a elipse sobrepor um dos eixos confirma que a diferença entre médias de $\delta^{13} \mathrm{Ce} \delta^{15} \mathrm{~N}$ dos tratamentos comparados é igual a zero e, assim, os tratamentos não diferem.

No ovo (Figura 1) e na gema (Figura 2), as médias do par isotópico do tratamento com inclusão de 1,5\% de farinha de carne e ossos bovinos não foram diferentes $(P>0,05)$ daquelas do tratamento controle, pois a região de confiança deste tratamento sobrepôs o eixo do gráfico com diferença igual a zero para o nitrogênio-15. A partir da inclusão de 3,0\% farinha de carne e ossos bovinos, as médias dos pares isotópicos distanciaram dos eixos do gráfico e foram estatisticamente diferentes $(\mathrm{P}<0,05)$ das obtidas no grupo com dieta de origem estritamente vegetal. Entretanto, todos os tratamentos experimentais da fração albúmen (Figura 3), ou seja, tratamentos com farinha de carne e ossos bovinos na dieta das aves foram diferentes $(\mathrm{P}<0,05)$ estatisticamente do tratamento controle.

As variações encontradas entre as frações não são bem compreendidas, pois, de acordo com Tieszen et al. (1983), as frações bioquímicas diferem isotopicamente entre si, e essas diferenças isotópicas do organismo podem ser reflexo de suas composições bioquímicas. Frações que possuem em sua composição menor quantidade de lipídeos

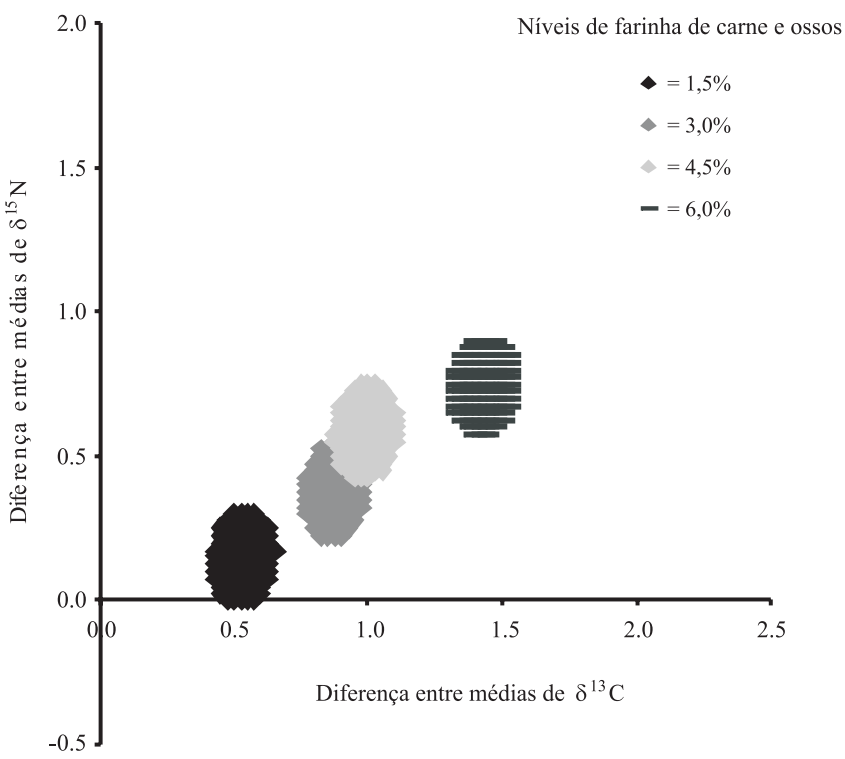

Figura 1 - Regiões de confiança formadas pela diferença entre os valores isotópicos de $\delta^{13} \mathrm{C}$ e $\delta^{15} \mathrm{~N}$ do ovo de cada tratamento em comparação ao tratamento controle $(\mathrm{n}=12)$.

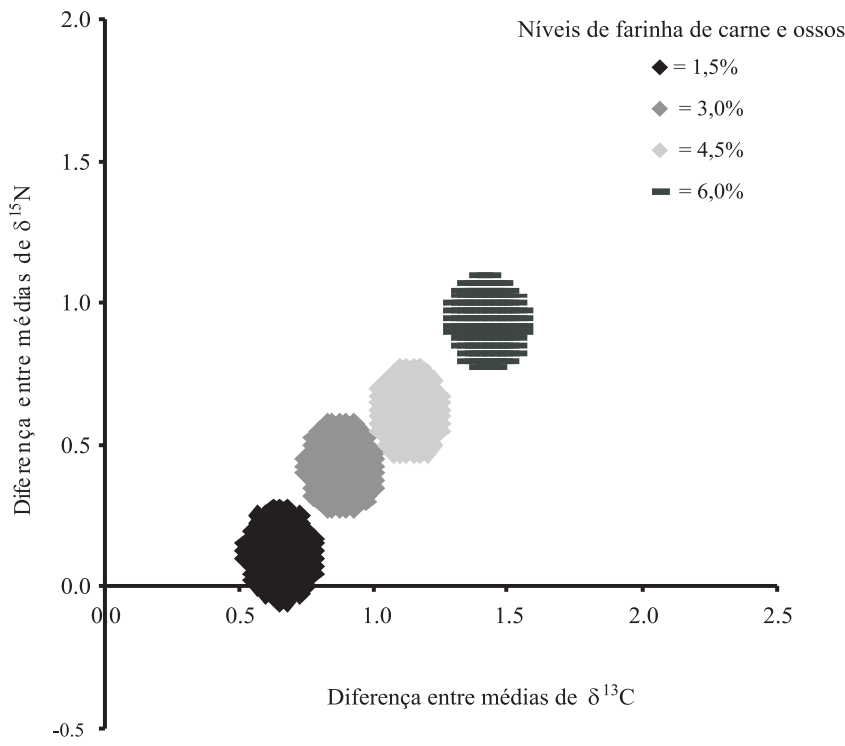

Figura 2 - Regiões de confiança formadas pela diferença entre os valores isotópicos de $\delta^{13} \mathrm{C}$ e $\delta^{15} \mathrm{~N}$ da gema de cada tratamento em comparação ao tratamento controle $(\mathrm{n}=12)$.

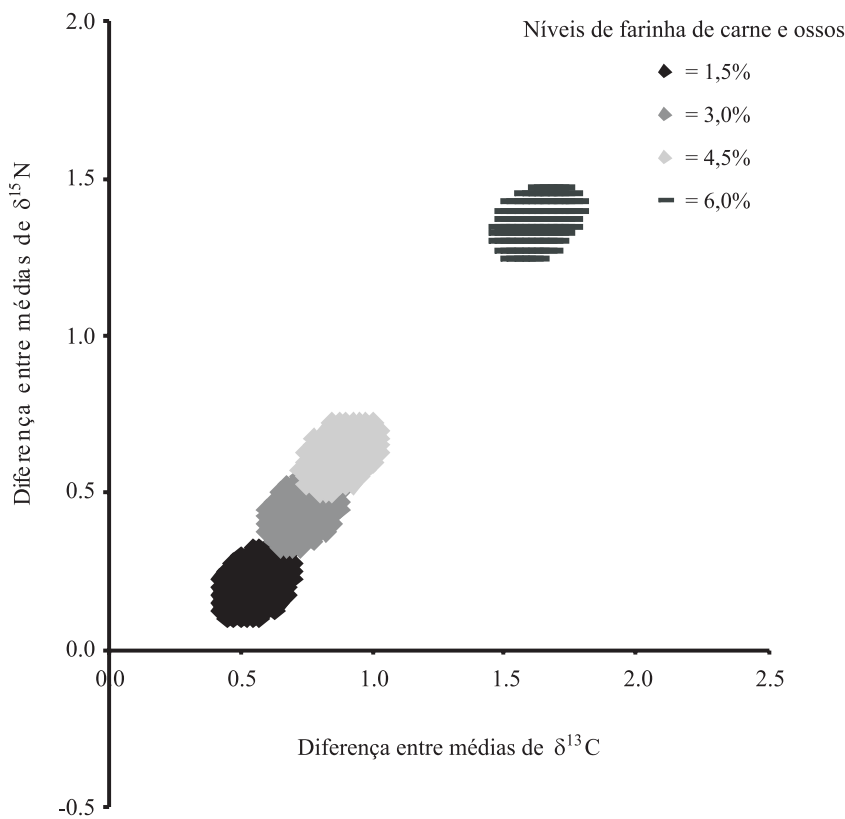

Figura 3 - Regiões de confiança formadas pela diferença entre os valores isotópicos de $\delta^{13} \mathrm{C}$ e $\delta^{15} \mathrm{~N}$ do albúmen de cada tratamento em comparação ao tratamento controle $(n=12)$.

provavelmente teriam valor de $\delta^{13} \mathrm{C}$ maior que a fração que apresente maior quantidade de lipídeos, sendo relativamente pobre em carbono-13. Todavia, a detecção no albúmen do nível de inclusão de 1,5\% de farinha de carne e ossos na dieta das poedeiras pode ter ocorrido pelo menor desvio- 
padrão dos valores de nitrogênio-15 nesta fração (Tabela 2), que geraram menor amplitude dos pontos gerados pela matriz de erro no programa estatístico SAS (1996).

O nível de deteç̧ão da farinha de carne e ossos encontrado em ovos neste trabalho foi menor que o observado por Carrijo et al. (2006) em frangos de corte (8\% de farinha de carne e ossos) e Móri et al. (2007; 2008) em codornas de corte, que foi de 4,5\%. A variação no nível de detecção pode ter ocorrido pela diferença de metabolismo dos tecidos e espécies animais comparados ou, ainda, pela diferença no número de repetições. Neste estudo, o número de amostras analisadas de cada fração para a formação das regiões de confiança (análise estatística) foi de 12, enquanto Carrijo et al. (2006) e Móri et al. (2007, 2008) utilizaram apenas quatro amostras por tratamento, o que pode ter melhorado a representatividade dos resultados encontrados nas amostras em relação à população.

A detecção de farinha de carne e ossos bovinos nos ovos e nas gemas pode ser um nível entre 1,5\% e 3,0\% de inclusão na dieta das aves, mas, para saber qual o real nível de detecção, sugerem-se estudos futuros com níveis crescentes entre estes valores.

A comparação dos dados de ovo, gema e albúmen indicou que a fração albúmen seria a mais apropriada na deteç̧ão da inclusão de farinha de carne e ossos bovinos na alimentação de poedeiras, pois diferenciou o menor nível inclusão desse subproduto $(1,5 \%)$ na dieta das aves, enquanto, para ovo e gema, a diferenciação ocorreu apenas a partir de 3,0\% de inclusão nos moldes experimentais. Além disso, desidrata rapidamente, diminuindo o tempo de secagem (24 horas para o albúmen e 48 horas para a gema e ovo), e possui baixos níveis de ácidos graxos, exceto na etapa de extração de gorduras no processo de preparo da amostra, o que ocasiona mais agilidade ao processo de rastreabilidade.

Para identificação da inclusão de ingredientes de origem animal na dieta de aves em fase de cria e recria, ou até mesmo em aves de corte, onde o ovo ou suas frações não pode ser utilizado, outros tecidos ou produtos animais poderiam ser estudados com essa finalidade. Para isso, é necessário conhecer o crescimento e a taxa metabólica de diferentes tecidos para sua melhor utilização. Tecidos como fígado, sangue e plasma poderiam ser utilizados para acompanhamento periódico (ex.: semanal) dos lotes de aves, por apresentarem turnover isotópico rápido. Nessa linha de raciocínio, o bico e os ossos poderiam trazer informações sobre a média isotópica das rações ministradas às aves durante todo o período de criação. Talvez as penas sejam interessantes nesses estudos, pois, dependendo do seu crescimento, as informações isotópicas das diversas fases de criação poderiam ficar registradas em determinados segmentos de sua extensão, de modo que representassem apenas aquela fase em particular. Isso também poderia colaborar para a detecção de trocas de dietas (dietas contendo farinha de carne e ossos bovinos para dietas vegetais e vice-versa) ao longo do período de criação. Além disso, com o uso de sangue, plasma e penas, seria possível colher amostras nas diversas etapas de criação, podendo compor estratégias de amostragem sem a necessidade de sacrifício, além de fácil aplicação, servindo como ferramenta de apoio às auditorias e certificação de criações de aves isentas de proteínas de origem animal na dieta.

\section{Conclusões}

Com o aumento percentual de farinha de carne e ossos nas dietas, ocorre enriquecimento isotópico crescente de carbono-13 e nitrogênio-15 nos ovos e suas frações, e isso é um indicativo de que a técnica dos isótopos estáveis permite rastrear a farinha de carne e ossos bovinos utilizada na alimentação de poedeiras no produto final, ou seja, ovos, gema e albúmen. No albúmen, o nível mínimo de detecção de farinha de carne e ossos é de $1,5 \%$, enquanto, no ovo e na gema, pode ser entre 1,5\% e 3,0\% de farinha de carne e ossos utilizada na dieta das aves.

\section{Agradecimentos}

A Evandro Tadeu Silva, técnico do Centro de Isótopos Estáveis, IBB, UNESP, campus de Botucatu, pela realização das análises isotópicas.

\section{Referências}

BLOCK JUNIOR, C. Monitoramento da qualidade de rações brasileiras para ruminantes por espectrometria de massa. In: SIMPÓSIO SOBRE MANEJO E NUTRIÇÃO DE AVES E SUÍNOS E TECNOLOGIA DA PRODUÇÃO DE RAÇÕES, 2002, Campinas. Anais... Campinas: Colégio Brasileiro de Nutrição Animal, 2002. p.251-252.

BRICOUT, J.; KOZIET, J. Control of the authenticity of orange juice by isotopic analysis. Journal of Agricultural Food Chemistry, v.35, p.758-760, 1987.

BROOKES, S.T.; BARRIE, A.; DAVIES, J.E. A rapid ${ }^{13} \mathrm{C} /{ }^{12} \mathrm{C}$ test for determination of corn-syrups in honey. Journal of the Association of Official Analytical Chemists, v.74, p.627-629, 1991.

CARRIJO, A.S.; PEZZATO, A.C.; DUCATTI, C. et al. Traceability of bovine meat and bone meal in poultry by stable isotope analysis. Revista Brasileira de Ciência Avícola, v.8, p.37-42, 2006.

CERUTTI, M. Aplicação de um programa de rastreabilidade na cadeia de frangos de corte. In: SIMPÓSIO SOBRE MANEJO E NUTRIÇÃO DE AVES E SUÍNOS E TECNOLOGIA DA PRODUÇÃO DE RAÇÕES, 2002, Campinas. Anais... Campinas: Colégio Brasileiro de Nutrição Animal, 2002. p.253-264. 
CHOI, W.J.; LEE, S.M.; RO, H.M. et al. Natural ${ }^{15} \mathrm{~N}$ abundances of maize and soil amended with urea and composted pig manure. Plant and Soil, v.245, p.223-232, 2002.

DENADAI, J.C.; DUCATTI, C.; CALDARA, F.R. et al. Certificação de ovos de poedeiras comerciais pela técnica dos isótopos estáveis. In: CONGRESSO DE PRODUÇÃO E CONSUMO DE OVOS - APA, 3., 2005, Indaiatuba. Anais... Indaiatuba: APA, 2005. p.80.

DENADAI, J.C.; DUCATTI, C.; PEZZATO, A.C. et al. Studies on carbon-13 turnover in eggs and blood of commercial layers. Revista Brasileira de Ciência Avícola, v.8, p.251-256, 2006.

DENIRO, M.J.; EPSTEIN, S. You are what you eat (plus a few \%o) the carbon isotope cycle in food chains. Geological Society of America, v.6, p.834, 1976. (Abstract).

DENIRO, M.J.; EPSTEIN, S. Influence of diet on the distribution of carbon isotopes in animals. Geochimica et Cosmichimica Acta, v.42, p.495-506, 1978.

DENIRO, M.J.; EPSTEIN, S. Influence of diet on the distribution of nitrogen isotopes in animals. Geochimica et Cosmichimica Acta, v.45, p.341-351, 1981.

DUCATTI, C. Isótopos estáveis ambientais. Botucatu: Instituto de Biociências, Universidade Estadual Paulista, 2004. 184p. [Apostila].

GOTTMANN, R.; PEZZATO, A.C.; DUCATTI, C. et al. Rastreabilidade de subprodutos de origem animal em dietas com levedura e trigo para frangos. Pesquisa Agropecuária Brasileira, v.43, p.1641-1647, 2008.

HANDLEY, L.L.; RAVEN, J.A. The use of natural abundance of nitrogen isotopes in plant physiology and ecology. Plant Cell and Environment, v.15, p.965-985, 1992.

KOZIET, J.; ROSSMANN, A.; MARTIN, G.J. et al. Determination of carbon-13 content of sugars of fruit and vegetable juices. Analytica Chimica Acta, v.271, p.31-38, 1993.

LICATTI, F. Isótopos estáveis do carbono $\left({ }^{13} \mathrm{C} /{ }^{12} \mathrm{C}\right)$ em plantas do ciclo bioquímico $\mathbf{C}_{3}$ e $\mathbf{C}_{4}$. 1997. 65f. Monografia (Bacharelado em Ciências Biológicas) - Instituto de Biociências/ Universidade Estadual Paulista, Botucatu.

MANCA, G.; CAMIN, F.; COLORU, G. et al. Characterization of the geographical origin of Pecorino Sardo cheese by casein stable isotope $\left({ }^{13} \mathrm{C} /{ }^{12} \mathrm{C}\right.$ and $\left.{ }^{15} \mathrm{~N} /{ }^{14} \mathrm{~N}\right)$ ratios and free amino acid ratios. Journal of Agricultural and Food Chemistry, v.49, p.1404-1409, 2001.

MARTIN, G.J.; GUILLOU, C.; MARTIN, M.L. et al. Natural factors of isotope fractionation and the characterization of wines. Journal of Agricultural and Food Chemistry, v.36, p.316-322, 1988.
MÓRI, C.; GARCIA, E.A.; DUCATTI, C. et al. Traceability of animal byproducts in quail (Coturnix coturnix japonica) tissues using carbon $\left({ }^{13} \mathrm{C} /{ }^{12} \mathrm{C}\right)$ and nitrogen $\left({ }^{15} \mathrm{~N} /{ }^{14} \mathrm{~N}\right)$ stable isotopes. Revista Brasileira de Ciência Avícola, v.9, p.263-269, 2007.

MÓRI, C.; GARCIA, E.A.; DUCATTI, C. et al. Poultry offal meal traceability in meat quail tissues using the technique of stable carbon $\left({ }^{13} \mathrm{C} /{ }^{12} \mathrm{C}\right)$ and nitrogen $\left({ }^{15} \mathrm{~N} /{ }^{14} \mathrm{~N}\right)$ isotopes. Revista Brasileira de Ciência Avícola, v.10, p.45-52, 2008.

OLIVEIRA, R.P.; DUCATTI, C.; PEZZATO, A.C. et al. Traceability of poultry offal meal in broiler feeding using isotopic analysis $\left(\delta^{13} \mathrm{C}\right.$ and $\left.\delta^{15} \mathrm{~N}\right)$ of different tissues. Revista Brasileira de Ciência Avícola, v.12, p.13-20, 2010.

PIASENTIER, E.; VALUSSO, R.; CAMIN, F. et al. Stable isotope ratio analysis for authentication of lamb meat. Meat Science, v.64, p.239-247, 2003.

ROSA, C.R.; MORAES, M.; NETO, J.A.G. et al. Effect of modifiers on thermal behavior of Se in acid digestates and slurry of vegetables by graphite furnace atomic absorption spectrometry. Food Chemistry, v.79, p.517-523, 2002.

ROSSMANN, A.; HABERHAUER, G.; HOLZL, S. et al. The potential of multielement stable isotope analysis for regional origin assgnment of butter. European Food Research \& Technology, v.211, p.32-40, 2000.

ROSTAGNO, H.S.; ALBINO, L.F.T.; DONZELE, J.L. et al. Tabelas brasileiras para aves e suínos: composição de alimentos e exigências nutricionais. Viçosa, MG: UFV, 2005. 186p.

STATISTICAL ANALYSIS SYSTEM - SAS. SAS/STAT: user's guide. Version 6.11. 4.ed., v.2. Cary: SAS Institute Inc., 1996. 842p.

TIESZEN, L.L.; BOUTTON, T.W.; TESDAHL, K.G. et al Fractionation and turnover of stable carbon isotopes in animal tissues: implications for $\delta^{13} \mathrm{C}$ analysis of diet. Oecologia, v.57, p.32-37, 1983.

VOGEL, J.C. Variability of carbon isotope fractionation during photosynthesis. In: EHLERINGER JR., A.; HALL, A.E.; FARQUHAR, G.D. (Eds.) Stable isotopes and plant carbonwater relations. San Diego: Academic Press, 1993. p.29-46.

WERNER, R.A.; SCHIMIDT, H.L. The in vivo nitrogen isotope discrimination among organic plant compounds. Phytochemistry, v.61, p.465-784, 2002.

WHITE, J.W.; WINTERS, K.; MARTIN, P. et al. Stable carbon isotope ratio analysis of honey: validation of internal standard procedure for worldwide application. Journal of the Association of Official Analytical Chemists International, v.81, p.610-619, 1998. 